\title{
Suez Canal blockage and its global impact on healthcare amidst the COVID-19 pandemic
}

\author{
Kimberly G. Ramos ${ }^{1} \oplus$, lan Christopher N. Rocha ${ }^{1} \oplus$, Trisha Denise D. Cedeño ${ }^{1}{ }^{\oplus}$,

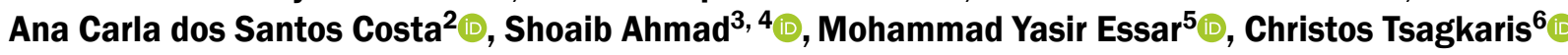

${ }^{1}$ School of Medicine, Centro Escolar University, Manila, Philippines

${ }^{2}$ Faculty of Medicine, Federal University of Bahia, Salvador, Bahia, Brazil

${ }^{3}$ Punjab Medical College, Faisalabad, Pakistan

${ }^{4}$ Faisalabad Medical University, Faisalabad, Pakistan

${ }^{5}$ Medical Research Centre, Kateb University, Kabul, Afghanistan

${ }^{6}$ Faculty of Medicine, University of Crete, Heraklion, Greece

It is estimated that $90 \%$ of the world's trade, including hospital supplies and medicines, is transported by sea and man-made waterways, such as the 193-kilometre-long (120 miles) Suez Canal, which cuts through Egypt and connects Mediterranean Sea to the Red Sea. This artificial channel in Egypt has played an important role in economic growth since its completion in 1869 , serving as an artery of world trade, including the healthcare industry, being a key transit point for ships moving goods from Asia, Middle East, and Europe [1, 2]. On an average day, the canal caters to nearly 50 vessels carrying essential commodities. It was responsible for the transit of over 19,000 ships in 2019 representing nearly a third of the world's container ship traffic, equating to nearly 1.25 billion metric tons of cargo, and accounting for about $12 \%$ to $13 \%$ of world trade per year [3].

However, on March 23, 2021, a 224,000-ton and 400-metre-long cargo ship Ever Given ran aground near the southern end of the Suez Canal due to low visibility and poor navigation amid 40-knot winds and a sandstorm [4], causing a blockage in the major waterway. Meanwhile, navigation through the Suez Canal was temporarily suspended and ships en-route the canal during this incident were escorted back to nearby anchorage areas [5]. This week-long incident resulted in a maritime traffic jam causing at least 422 cargo vessels carrying oil and consumer goods to be stranded, holding up an estimated $\$ 9.6$ billion of trade daily. It has also forced multiple operators to reroute vessels around Africa's Cape of Good Hope travelling an extra 6,000 miles, and substantially extending navigation time to about 3 weeks [6-8]. Aside from the global trade, countless retailers also suffered losses due to the blockage as key shipments were delayed. The extent of economic loss due to the blockage is likely to be even higher when costs such as additional shipping operation charges, commodity prices and shipping delays are factored in [8].

Fortunately, the Suez Canal blockage was resolved on March 29, 2021. Tugboats were used to re-float the vessel, while dredges excavators have been removing sand and mud from around the port side [5]. However, its impact still constitutes a global concern. The obstruction of the canal has caused a global shortage of essential commodities, including medical and surgical supplies and medicines, which are essential during the coronavirus disease 2019 (COVID-19) pandemic. Several countries currently suffering from the global public health emergency were greatly affected due to the delay of shipment of hospital and pharmaceutical supplies caused by the Suez Canal blockage [9].

Given the crucial role of the shipping industry in the timely delivery of healthcare resources and the detrimental effect triggered by a single vessel, healthcare industry and stakeholders have found themselves to a precarious position [10]. On top of the financial losses, frontline workers have found themselves in short of personal protective equipment, non-COVID-19 wards have experienced even more difficulties in maintaining their functionality, and outpatient and informal/at-home care have been affected by shortages. In a word, healthcare delivery could have been

Dr. Mohammad Yasir Essar, Medical Research Centre, Kateb University, Kabul, Afghanistan, e-mail: m.yasir.essar@kateb.edu.af

This article is available in open access under Creative Common Attribution-Non-Commercial-No Derivatives 4.0 International (CC BY-NC-ND 4.0) license, allowing to download articles and share them with others as long as they credit the authors and the publisher, but without permission to change them in any way or use them commercially. 
compromised, if the blockage lasted longer [11]. Therefore, this incident has exposed the long-standing vulnerability of the medical product supply chain [12].

Aside from its current impact on medical and drug supplies, the delays can affect the COVID-19 vaccines Iogistics. International bodies, national governments, and companies might hesitate to entrust vaccines transportation to the shipping industry. Using airlines instead of vessels in such a short notice will put a - potentially unbearable - burden on aviation [13, 14]. The whole situation calls into question the goal to deliver the right care to the right person at the right time. Patients experience higher morbidity and mortality risk due to potentially substandard quality of care, reuse of medical products, and increased risk of substitute equipment-related error. These are systemic risks that we have to consider if we are looking into developing effective long-term solutions $[15,16]$.

The Suez Canal blockage crisis has highlighted the importance of shipping in the global economy and in the healthcare industry. This incident stressed the need to enhance the resilience of the supply chain, especially in case of disruption of just-in-time production during the COVID-19 pandemic. This issue poses several industries, including pharmaceutical and medical technology companies at risk. Consequently, these entities might abandon their plans to ship COVID-19 vaccines via cargo ships in fear of similar incidents in the future. This could backfire into more delay with the shipping of vaccines globally. As a result of this, the quality of medical supplies could be greatly affected, especially when it comes to COVID-19 vaccines which need consistent storage conditions. Hence, stakeholders should analyse this incident in greater detail and devise contingency plans in anticipation of similar incidents. Hampering global transactions and supplies comprises great risk and healthcare nowadays cannot afford such a risk.

\section{REFERENCES}

1. Why Suez Canal? Suez Canal Authority. https://www.suezcanal.gov. eg/English/About/Pages/WhySuezCanal.aspx (cited 2021 Apr 04).

2. Kaus hik M. The Suez Canal: a man-made marvel connecting the Mediterranean and Red Sea. Maritime Insight. 2020 Dec 19. https:// www.marineinsight.com/maritime-history/a-brief-history-of-the-suez-canal/ (cited 2021 Apr 04).

3. Hopcraft R, Jones K, Tam K. Suez Canal container ship accident is a worst-case scenario for global trade. The Conversation. 2021 Mar 25. https://theconversation.com/suez-canal-container-ship- -accident-is-a-worst-case-scenario-for-global-trade-157802 (cited 2021 Apr 04).

4. Picheta R. Why the Suez Canal is so important - and why its blockage could be so damaging. CNN. 2021 Mar 26. https://edition.cnn. com/2021/03/26/africa/suez-canal-importance-explainer-scli-intl/ index.html (cited 2021 Apr 04).

5. Leonard M. Timeline: how the Suez Canal blockage unfolded across supply chains. Supply Chain Dive. 2021 Apr 01. https://www.supplychaindive.com/news/timeline-ever-given-evergreen-blocked-suez-canal-supply-chain/597660/(cited 2021 Apr 04).

6. Tuttle R. Why a canal built in 1869 is more important than ever. Bloomberg. 2021 Mar 26. https://www.bloomberg.com/news/ articles/2021-03-26/what-is-the-suez-canal-and-why-is-it-so-important-quicktake (cited 2021 Apr 04).

7. Suez Canal ends shipping backlog: statement. Reuters. $2021 \mathrm{Apr}$ 03. https://www.reuters.com/article/idUSKBN2BQOBW (cited 2021 Apr 04).

8. Das K. Explained: how much did Suez Canal blockage cost world trade. India Today. 2021 Mar 30. https://www.indiatoday.in/ business/story/explained-how-much-did-suez-canal-blockage-cost-world-trade-1785062-2021-03-30 (cited 2021 Apr 07).

9. Veiga A. Suez Canal blockage adds to pressure points in global trade. AP News. 2021 Mar 29. https://apnews.com/article/europe-global-trade-egypt-coronavirus-pandemic-suez-canal-166bc8f21e9705f2921a67ef2dea176c (cited 2021 Apr 07).

10. Kickham V. Supply chains brace for ripple effects of Suez Canal blockage. DC Velocity. 2021 Apr 01. https://www.dcvelocity.com/ articles/50093-supply-chains-brace-for-ripple-effects-of-suez-canal-blockage (cited 2021 Apr 04).

11. Miller FA, Young SB, Dobrow M, et al. Vulnerability of the medical product supply chain: the wake-up call of COVID-19. BMJ Qual Saf. 2021; 30(4): 331-335, doi: 10.1136/bmjqs-2020-012133, indexed in Pubmed: 33139342.

12. Shortage of personal protective equipment endangering health workers worldwide. World Health Organization. 2020 Mar 03. https://www.who.int/news/item/03-03-2020-shortage-of-personal-protective-equipment-endangering-health-workers-worldwide (cited 2021 Apr 05).

13. Lo C. Shipping's role in COVID-19 vaccine logistics: key questions answered. Ship Technology. 2021 Mar 02. https://www.ship-technology.com/features/shipping-role-covid19-vaccine-logistics-key-questions-answered/ (cited 2021 Apr 07).

14. New solution revealed for COVID-19 vaccine transportation. Safety4Sea. 2020 Dec 29. https://safety4sea.com/new-solution-revealed-for-covid-19-vaccine-transportation/ (cited $2021 \mathrm{Apr} 07$ ).

15. Sharma N, Hasan Z, Velayudhan A, et al. Personal protective equipment: challenges and strategies to combat COVID-19 in India: a narrative review. J Health Manag. 2020; 22(2): 157-168, doi: 10.1177/0972063420935540.

16. Phuong JM, Penm J, Chaar B, et al. The impacts of medication shortages on patient outcomes: A scoping review. PLoS One. 2019; 14(5): e0215837, doi: 10.1371/journal.pone.0215837, indexed in Pubmed: 31050671. 